\title{
Antimicrobial Susceptibility of Lactic Acid Bacteria Strains of Potential Use as Feed Additives - The Basic Safety and Usefulness Criterion
}

\author{
Ilona Stefańska ${ }^{1 *}$, Ewelina Kwiecień ${ }^{1}$, Katarzyna Jóźwiak-Piasecka ${ }^{2}$, Monika Garbowska $^{3}$, \\ Marian Binek ${ }^{1}$ and Magdalena Rzewuska ${ }^{1}$
}

${ }^{1}$ Department of Preclinical Sciences, Institute of Veterinary Medicine, Warsaw University of Life Sciences, Warsaw, Poland, ${ }^{2}$ Department of Fermentation Technology, Prof. Waclaw Dabrowski Institute of Agriculture and Food Biotechnology - State Research Institute, Warsaw, Poland, ${ }^{3}$ Division of Milk Biotechnology, Department of Biotechnology, Microbiology and Food Evaluation, Institute of Food Sciences, Warsaw University of Life Sciences, Warsaw, Poland

OPEN ACCESS

Edited by:

James Allen Byrd,

Agricultural Research Service,

United States Department of

Agriculture, United States

Reviewed by:

Kumaragurubaran Karthik, Tamil Nadu Veterinary and Animal

Sciences University, India David Smith

Heriot-Watt University, United Kingdom

*Correspondence: Ilona Stefańska ilona_stefanska@sggw.edu.p

Specialty section This article was submitted to Veterinary Infectious Diseases,

a section of the journal

Frontiers in Veterinary Science

Received: 28 March 2021 Accepted: 04 June 2021 Published: 01 July 2021

Citation:

Stefańska I, Kwiecień E. Jóźwiak-Piasecka K, Garbowska M

Binek M and Rzewuska M (2021)

Antimicrobial Susceptibility of Lactic Acid Bacteria Strains of Potential Use as Feed Additives - The Basic Safety

and Usefulness Criterion.

Front. Vet. Sci. 8:687071.

doi: 10.3389/fvets.2021.687071
The spread of resistance to antibiotics is a major health concern worldwide due to the increasing rate of isolation of multidrug resistant pathogens hampering the treatment of infections. The food chain has been recognized as one of the key routes of antibiotic resistant bacteria transmission between animals and humans. Considering that lactic acid bacteria ( $\angle A B)$ could act as a reservoir of transferable antibiotic resistance genes, $L A B$ strains intended to be used as feed additives should be monitored for their safety. Sixty-five LAB strains which might be potentially used as probiotic feed additives or silage inoculants, were assessed for susceptibility to eight clinically relevant antimicrobials by a minimum inhibitory concentration determination. Among antimicrobial resistant strains, a prevalence of selected genes associated with the acquired resistance was investigated. Nineteen LAB strains displayed phenotypic resistance to one antibiotic, and 15 strains were resistant to more than one of the tested antibiotics. The resistance to aminoglycosides and tetracyclines were the most prevalent and were found in 37 and $26 \%$ of the studied strains, respectively. Phenotypic resistance to other antimicrobials was found in single strains. Determinants related to resistance phenotypes were detected in 15 strains as follows, the aph( $\left.3^{\prime \prime}\right)$-Illa gene in 9 strains, the Inu(A) gene in three strains, the $\operatorname{str}(\mathrm{A})-\operatorname{str}(\mathrm{B}), \operatorname{erm}(\mathrm{B}), \operatorname{msr}(\mathrm{C})$, and tet( $\mathrm{M})$ genes in two strains and the tet $(\mathrm{K})$ gene in one strain. The nucleotide sequences of the detected genes revealed homology to the sequences of the transmissible resistance genes found in lactic acid bacteria as well as pathogenic bacteria. Our study highlights that $L A B$ may be a reservoir of antimicrobial resistance determinants, thus, the first and key step in considering the usefulness of $L A B$ strains as feed additives should be an assessment of their antibiotic resistance. This safety criterion should always precede more complex studies, such as an assessment of adaptability of a strain or its beneficial effect on a host. These results would help in the selection of the best LAB strains for use as feed additives. Importantly, presented data can be useful for revising the current microbiological cut-off values within the genus Lactobacillus and Pediococcus.

Keywords: acquired resistance genes, antimicrobial susceptibility testing, food additives, minimum inhibitory concentration, lactic acid bacteria, probiotics, reservoir of resistance determinants 


\section{INTRODUCTION}

Lactic acid bacteria (LAB) strains are important industrial microorganisms, and they have a long history of safe use as feed additives. They are commonly used as probiotics, animal growth biopromoter, as well as bacterial inoculants for forage ensiling to improve not only the quality but also safety of feed $(1,2)$. Many LAB species are part of the resident microbiota of the gastrointestinal and genitourinary tracts of humans and animals, where they are thought to exert many health-associated beneficial effects (2). Moreover, they have ability to inhibit other microorganisms, including pathogens that cause foodborne diseases or food spoilage (3).

Among the different genera belonging to the LAB group, mainly Lactobacillus spp. and Pediococcus spp. have been register as gut biota stabilizers and silage additives (4). The interest in the application of pediococci in animal husbandry is gradually increasing due to the improvement of the characteristics and growth abilities of animals that can be achieved with their use (5). They were shown to be effective as probiotics for broiler chickens, laying hens, piglets, fish, crustaceans, and as silage additives (4). Moreover, many strains produce bacteriocins or bacteriocin-like substances that have well-recognized pathogen inhibitory activities (5). Although Enterococcus spp. strains as human probiotics remain controversial, in a point of view of the opportunistic and nosocomial infections caused by these bacteria, they are used as silage additives and probiotics for stabilizing the microbial communities of the gastrointestinal tract of animals $(4,6)$.

Increasing awareness of probiotics and their therapeutic and prophylactic properties constantly encourages the search for new LAB strains, with beneficial health properties and safe for animal consumption. A wide variety of LAB is used in animal nutrition, either directly or as a source of feed additives. Most LAB species are granted the GRAS status (Generally Regarded As Safe) provided by the US Food and Drug Administration (FDA) and within Europe "QPS status (Qualified Presumption of Safety)" notified by European Food Safety Authority (EFSA), The Panel on Biological Hazards (BIOHAZ), which means that they are considered safe for human and animal consumption and for the environment (7).

Despite that LAB species are widely used and recognized as safe food and feed additives, the rare cases of serious infections in humans caused by LAB have been described in the literature, including bacteremia (8-11), endocarditis (12, 13), pleuropneumonia $(8,14)$, meningitis (15), and urinary tracts infections (16). The infections occur mainly in patients with serious underlying illnesses, the immunocompromised ones, premature newborns, or elderly individuals. In case of Lactobacillus spp. most of the reported clinical cases are related to Lactobacillus rhamnosus. Infections associated with Lactococcus spp. are mainly concerned to Lactobacillus lactis subsp. lactis and Lactobacillus garvieae, while infections caused by Pediococcus spp. and Leuconostoc spp. have rarely been described $(17,18)$. Little is known about the role of LAB in animal infections, although the genus Lactococcus may be associated with bovine mastitis and infections in fish and birds (19), up to date there are no reports of Lactobacillus and Pediococcus infections in animals.

The second serious concern is acquired resistance to antimicrobials of human and veterinary importance among LAB strains (20). There has been increasing attention to this phenomenon since $\mathrm{LAB}$ are considered as a reservoir of resistance genes that can be transferred to pathogenic bacteria, leading to the spread of antibiotic resistance among pathogens and complicating the treatment of infection caused by these bacteria (19). Therefore, caution is needed in selecting and monitoring potentially probiotic strains, and antimicrobial resistance (AMR) is regarded as a crucial safety issue during assessing and approving LAB as feed additives (21). The safety assessment of microbial feed additives is governed under specific EU regulatory frameworks in accordance with Regulation (WE) No 1831/2003 and Commission Regulation (EC) No 429/2008. The Panel on Additives and Products or Substances used in Animal Feed (FEEDAP) provides the scientific opinion on the efficacy of feed additives and their safety to target animals, the consumers of products derived from animals treated with the additives, and to the environment. In line with the FEEDAP recommendation, any bacterial strain carrying an acquired gene conferring AMR or strains with the unknown genetic nature of a demonstrated resistance to antimicrobial agents should not be used as a feed additive due to the greatest risk of horizontal spread (21).

The aim of the present study was an AMR safety assessment of selected $\mathrm{LAB}$ strains intended for use as feed additives by phenotypic screening of resistance to clinically relevant antimicrobials. The identification of resistance determinants in the resistant $\mathrm{LAB}$ strains was also performed in order to exclude the presence of potentially transferable AMR genes.

\section{MATERIALS AND METHODS}

\section{Bacterial Strains}

The study provides a safety assessment of 65 LAB strains potentially useful as probiotics and other feed additives. Fifty-seven Lactobacillus strains [Lactobacillus plantarum ( $n=26)$, Lactobacillus fermentum $(n=7)$, Lactobacillus casei $(n=3)$, L. rhamnosus $(n=3)$, Lactobacillus reuteri $(n=3)$, Lactobacillus brevis $(n=3)$, Lactobacillus buchneri $(n=2)$, Lactobacillus salivarius $(n=2)$, Lactobacillus agilis $(n=2)$, Lactobacillus acidophilus $(n=1)$, Lactobacillus johnsonii $(n=1)$, Lactobacillus diolivorans $(n=1)$, Lactobacillus delbrueckii $(n=$ 1), Lactobacillus paracasei $(n=1)$, Lactobacillus farraginis ( $n$ $=1)$, six Pediococcus strains [Pediococcus pentosaceus $(n=5)$, Pediococcus acidilactici $(n=1)]$, and two Enterococcus strains [one Enterococcus durans strain and one Enterococcus faecium strain] were selected for this study (Supplementary Table 1). A total of 47 strains are available at the culture collections: 42 strains at the Collection of Industrial Microbial Cultures (KKP), located at the prof. Waclaw Dabrowski Institute of Agricultural and Food Biotechnology (IAFB) in Warsaw (Poland), four strains at the Polish Collection of Microorganisms (PCM), located at the Institute of Immunology and Experimantal Therapy in Wroclaw (Poland) and one strain from American Type Culture Collection 
(ATCC). The rest 18 strains were isolated from fermented or fresh vegetables and fruits $(n=14)$ or probiotic drinks $(n=$ 4 ). The isolates were identified by nucleotide sequence analysis of the gene encoding $16 \mathrm{~S}$ rRNA. LAB strains belonging to the L. plantarum phylogenetic group (L. plantarum, Lactobacillus pentosus, and Lactobacillus paraplantarum) were differentiated by multiplex PCR using species-specific primers amplified the fragment of the recA gene encoding the recombinase A (22). The strains isolated from the same sources were typed by RAPD-PCR (Random Amplified Polymorphic DNA) with primers RP and PRIMO2 (23) in order to confirm their intraspecies diversity (data not shown). All strains were stored in a liquid nitrogen atmosphere in MRS (deMan- Rogosa-Sharpe) broth (Oxoid) supplemented with glycerol $(15 \% \mathrm{v} / \mathrm{v})$. Before the antibiotic susceptibility assay, LAB strains were cultivated in MRS agar (Oxoid) at $37^{\circ} \mathrm{C}$ for $24-48 \mathrm{~h}$ in $5 \% \mathrm{CO}_{2}$. After incubation, the colonies were suspended in $0.85 \% \mathrm{NaCl}$ solution to prepare the inoculum for the broth microdilution test.

\section{Phenotypic Antimicrobial Resistance}

The following antimicrobials, used in therapy of common infections, were tested: gentamicin (0.125-64 mg/L), kanamycin (0.5-256 mg/L), streptomycin $(0.5-256 \mathrm{mg} / \mathrm{L})$, tetracycline (0.125-64 mg/L), chloramphenicol (0.06-32 mg/L), ampicillin (0.015-8 mg/L), erythromycin $(0.015-8 \mathrm{mg} / \mathrm{L})$, and clindamycin (0.015-8 mg/L). Gentamicin, kanamycin, erythromycin, clindamycin originated from the European Pharmacopoeia (EP) Reference Standards, while streptomycin, tetracycline, chloramphenicol, and ampicillin from Sigma-Aldrich. LSM broth (IsoSensitest broth (90\%) and MRS broth (10\%), adjusted to $\mathrm{pH}$ 6.7) and the microdilution method according to Klare et al. (24) were used. The lowest concentration of each antibiotics that inhibits the visible growth of bacteria (MIC, Minimum Inhibitory Concentration) was determined after $48 \mathrm{~h}$ of incubation at $37^{\circ} \mathrm{C}$ and in the presence of $5 \% \mathrm{CO}_{2}$. Susceptibility of strains was established in accordance with the microbiological cut-off values defined by the EFSA Panel on Additives and Products or Substances used in Animal Feed (21). The accuracy of antimicrobial susceptibility testing was monitored by parallel use of the reference strains, Enterococcus faecalis ATCC 29212 and Escherichia coli ATCC 25922 as a quality control. The study was performed in triplicate. The differences of MICs for independent sample never exceed 1 order of dilution.

\section{Genetic Determinants of Antimicrobial Resistance}

All LAB strains phenotypically resistant to the tested antimicrobial agents were examined by PCR for the presence of selected AMR genes. The following genes were detected: bla gene (ampicillin-resistant strains); the $\operatorname{erm}(\mathrm{A}), \operatorname{erm}(\mathrm{B})$, $\operatorname{erm}(\mathrm{C}), m s r$ genes, and the $\operatorname{lnu}(\mathrm{A})$ gene (erythromycin and/or clindamycin-resistant strains); genes encoding ribosomal protection proteins (universal primer set and subsequently, specific primers for tet $(\mathrm{W})$ and tet $(\mathrm{M})$ genes for positive strains) and the tet $(\mathrm{K})$ and tet $(\mathrm{L})$ genes encoding a tetracycline efflux pump (tetracycline-resistant strains); the cat gene (chloramphenicol-resistant strains); the aph( $\left.3^{\prime \prime}\right)-I I I a$ gene (kanamycin-resistant strains); the $\operatorname{ant}(6), \operatorname{str}(\mathrm{A}) / \operatorname{str}(\mathrm{B})$ and $\operatorname{aad}(\mathrm{A})$ genes (streptomycin-resistant strains); the $\operatorname{aac}\left(6^{\prime}\right)$ $a p h\left(2^{\prime \prime}\right)$ gene (aminoglycosides-resistant strains). In case of the detection of resistance genes, the cut-off values given in the previous EFSA guidance (25) were additionally used for a results analysis.

The characteristics of the primers used in the study and appropriate references (26-36) are shown in Supplementary Table 2 . The primer set for $m s r(C)$ detection was designed using the PCR Primer Design Tool (https:// eurofinsgenomics.eu/en/ecom/tools/pcr-primer-design) and checked using an Oligo Analysis Tool (https://eurofinsgenomics. eu/en/ecom/tools/oligo-analysis). PCR reactions were performed in a total volume of $25 \mu \mathrm{L}$ containing $1 \mu \mathrm{L}$ of each primer $(10$ $\mathrm{pmol} / \mu \mathrm{L}), 12.5 \mu \mathrm{L}$ of DreamTaq PCR Master Mix $(2 \times)$ (ThermoFisher Scientific) or JumpStart REDTaq ReadyMix Reaction Mix $(2 \times)$ (Sigma-Aldrich) and $50 \mathrm{ng}$ of DNA template. A template bacterial genomic DNA was purified using GenElute $^{\mathrm{TM}}$ Bacterial Genomic DNA Kits (Sigma-Aldrich) following the manufacturer's instruction for Gram-positive bacteria cells (pre-incubation with lysozyme). The amount and quality of DNA was determined using the Thermo Scientific NanoDrop ${ }^{\text {TM }} 1000$ Spectrophotometer.

PCR products were separated by electrophoresis on a $1 \%$ agarose gel (Sigma-Aldrich), stained with ethidium bromide, in TBE buffer $(100 \mathrm{~V})$. The O'RangeRuler ${ }^{\text {TM }}$ 200bp DNA Ladder, GeneRuler ${ }^{\mathrm{TM}} 100$ bp DNA Ladder or GeneRuler ${ }^{\mathrm{TM}}$ 100 bp Plus DNA Ladder (ThermoFisher Scientific) were used as size standard markers. Additionally, PCR products were purified and sequenced (Genomed S.A.). The obtained DNA sequences were analyzed using BLASTn (Basic Local Alignment Search Tool, http://blast.ncbi.nlm.nih.gov/Blast.cgi) and compared with sequences available in GenBank (National Center for Biotechnology Information) and CARD database (The Comprehensive Antibiotic Resistance Database, https:// card.mcmaster.ca) (Supplementary Table 3).

\section{Nucleotide Sequence of AMR Genes}

The nucleotide sequences of the $m s r(\mathrm{C}), \operatorname{erm}(\mathrm{B}), \ln u(\mathrm{~A}), \operatorname{aph}\left(3^{\prime \prime}\right)-$ $I I I a, \operatorname{str}(\mathrm{B}), \operatorname{tet}(\mathrm{M})$, and $\operatorname{tet}(\mathrm{K})$ genes described in this study are shown in Supplementary Table 4.

\section{RESULTS}

\section{Phenotypic Antimicrobial Resistance}

Each strain was able to grow on LSM medium without antibiotic (growth positive control). The MICs of antibiotics for studied strains are presented in Table 1 and Supplementary Table 5. The MIC ranges for particularly antibiotics were varied and were within the used concentration ranges of tested antibiotics: for gentamicin $<0.125-32 \mathrm{mg} / \mathrm{L}$, for kanamycin $4-\geq 256 \mathrm{mg} / \mathrm{L}$, for streptomycin $<0.5-\geq 256 \mathrm{mg} / \mathrm{L}$, for tetracycline $0.25-32$ $\mathrm{mg} / \mathrm{L}$, for chloramphenicol $1-8 \mathrm{mg} / \mathrm{L}$, for ampicillin $<0.015-\geq 8$ $\mathrm{mg} / \mathrm{L}$, for erythromycin $<0.015-\geq 8 \mathrm{mg} / \mathrm{L}$, and for clindamycin $<0.015-\geq 8 \mathrm{mg} / \mathrm{L}$ (Table 2 ). Only 31 strains (17 L. plantarum, four $L$. fermentum and $L$. casei, three $L$. reuteri and one 
TABLE 1 | Distribution of MICs of tested antibiotics among phenotypically resistant LAB strains $(n=34)$.

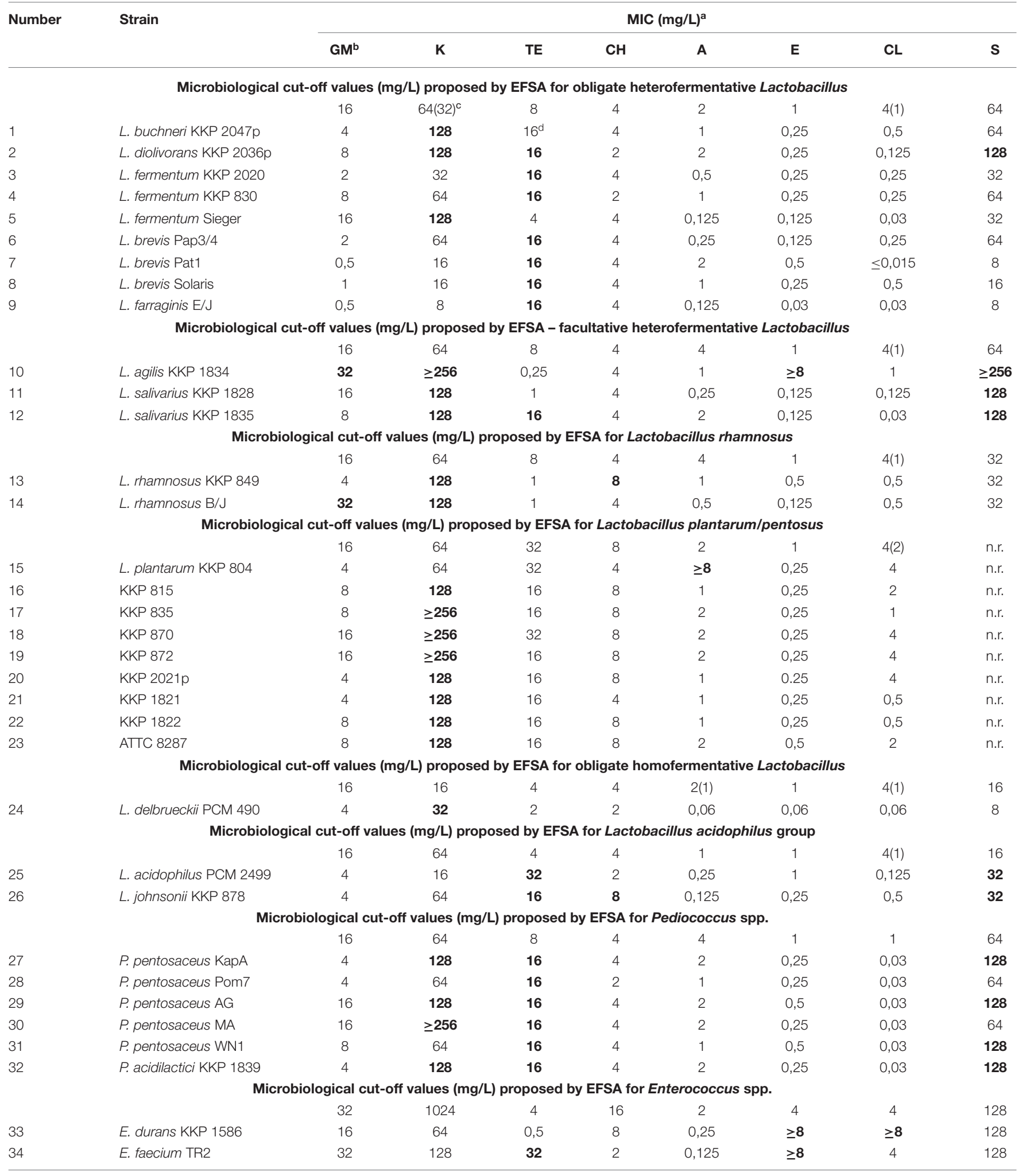

${ }^{a}$ MICS higher than EFSA cut-off values in bold; 'b GM, gentamicin; $K$, kanamycin; TE, tetracycline; $C H$, chloramphenicol; $A$, ampicillin; E, erythromycin; CL, clindamycin; S, streptomycin; ${ }^{c}$ the previous EFSA proposed cut-off values (2012) are given in brackets; ${ }^{d} L$. buchneri the cut-off for tetracycline is 128; KKP - strains from the Culture Collection of Industrial Microorganisms; PCM - strains from The Polish Collection of Microorganisms; n.r., not required. 
TABLE 2 | Distribution of the MIC, MIC 50 , and $\mathrm{MIC}_{90}$ values of eight antibiotics among studied LAB species $(n=65)$.

\begin{tabular}{|c|c|c|c|c|c|c|c|c|c|c|c|c|c|c|c|c|c|}
\hline \multirow[t]{2}{*}{ Antibiotic } & \multicolumn{17}{|c|}{ MIC values (mg/L) } \\
\hline & 0,015 & 0,003 & 0,06 & 0,0125 & 0,25 & 0,5 & 1 & 2 & 4 & 8 & 16 & 32 & 64 & 128 & 256 & $\mathrm{MIC}_{50}$ & $\mathrm{MIC}_{90}$ \\
\hline Gentamicin & & & & 1 & & 3 & 8 & 10 & 19 & 16 & 7 & 3 & & & & 4 & 16 \\
\hline Kanamycin & & & & & & & & & 2 & 1 & 8 & 14 & 21 & 16 & 5 & 64 & 128 \\
\hline Streptomycin ${ }^{a}$ & & & & & & 1 & & & 2 & 4 & 6 & 11 & 6 & 9 & 1 & 32 & 128 \\
\hline Tetracycline & & & & & 2 & 2 & 8 & 3 & 5 & 3 & 37 & 7 & & & & 16 & 32 \\
\hline Erythromycin & 1 & 2 & 4 & 20 & 30 & 5 & 2 & & & 3 & & & & & & 0,25 & 1 \\
\hline Clindamycin & 6 & 13 & 5 & 7 & 9 & 14 & 4 & 3 & 5 & 1 & & & & & & 0,25 & 2 \\
\hline Ampicillin & 1 & 1 & 3 & 14 & 10 & 5 & 17 & 14 & 1 & 1 & & & & & & 0,5 & 2 \\
\hline Chloramphenicol & & & & & & & 2 & 13 & 34 & 18 & & & & & & 4 & 8 \\
\hline
\end{tabular}

a27 L. plantarum strains were not tested.

L. buchneri, L. agilis and L. rhamnosus) out of 65 strains were susceptible to all antibiotics as the microbiological cut-off values were below the proposed by the FEEDAP Panel breakpoints (21). Nineteen LAB strains were resistant to one of the investigated antibiotics (i.e., 11 strains to kanamycin, seven to tetracycline and one to ampicillin), whereas 15 strains displayed resistance to more than one of the investigated antibiotics (i.e., 8 strains to two antibiotics, 6 strains to three and one strain to four antibiotics) (Tables 1, 3). The resistance to aminoglycosides was the most prevalent (37\%), since 21 strains (32\%) were resistant to kanamycin, 10 to streptomycin (15\%) and two to gentamicin (3\%). The Lactobacillus agilis KKP 1834 strain was highly resistant to all aminoglycosides tested, as the MIC values were twice higher than the corresponding breakpoints proposed by the EFSA. The tetracycline resistance was the second common antibiotic resistance found in the studied LAB strains, and was reported in 17 resistant strains $(26 \%)$. The resistance to erythromycin or chloramphenicol was reported in two strains, while single strains were phenotypically resistant to clindamycin or ampicillin. The MIC, $\mathrm{MIC}_{50}$, and $\mathrm{MIC}_{90}$ values of tested antibiotics for all studied strains are shown in Tables 1, 2.

\section{Distribution of AMR Genes}

To identify determinants responsible for the displayed resistance phenotypes, the strains were screened by PCR for the presence of selected AMR genes. Acquired AMR genes were only found in 15 strains (Table 3). When investigating 17 tetracycline-resistant strains, the tet $(\mathrm{M})$ gene encoding ribosomal protection proteins were found in two strains ( $L$. salivarius KKP 1835 with tetracycline MIC value of $16 \mathrm{mg} / \mathrm{L}$ and E. faecium TR2 with MIC value of $32 \mathrm{mg} / \mathrm{L}$ ). L. acidophilus 2499 strain displaying the MIC value of tetracycline three times higher than the breakpoint ( 32 vs. $4 \mathrm{mg} / \mathrm{L}$ ), was positive for the tet $(\mathrm{K})$ gene. The $\operatorname{erm}(\mathrm{B})$ gene was detected in L. plantarum KKP 2021p (the MIC value of clindamycin was $4 \mathrm{mg} / \mathrm{L}$, but the strain was susceptible to erythromycin, $\mathrm{MIC}=0.25 \mathrm{mg} / \mathrm{L}$ ) and in E. durans $\mathrm{KKP} 1586$ (erythromycin and clindamycin MIC values were $8 \mathrm{mg} / \mathrm{L}$ and higher than $8 \mathrm{mg} / \mathrm{L}$, respectively). In addition, two L. plantarum strains resistant to clindamycin (870 and 872 , with MIC value 4 $\mathrm{mg} / \mathrm{L}$ ) and E. faecium TR2, susceptible to clindamycin, carried the $\ln u(\mathrm{~A})$ gene. Two strains were positive for the $m s r(\mathrm{C})$ gene, L.agilis KKP 1834 and E. faecium TR2 strains (erythromycin MIC value was $8 \mathrm{mg} / \mathrm{L})$. The $a p h\left(3^{\prime \prime}\right)$-IIIa gene was detected in 9 strains belonging to the species: L. plantarum $(n=3)$, L. fermentum $(n$ $=3)$, L. buchneri $(n=1)$, L. diolivorans $(n=1)$, and L. agilis $(n=$ 1). Two strains, L. acidophilus 2499 and L. salivarius 1835, with streptomycin MIC values 32 and $128 \mathrm{mg} / \mathrm{L}$, respectively, were positive for $\operatorname{str}(\mathrm{A}) / \operatorname{str}(\mathrm{B})$ genes.

The selected PCR amplicons were sequenced, and the obtained sequences of the tested AMR genes (Supplementary Table 4) indicates the homology to the DNA sequences detected in other LAB, as well as in pathogens (Supplementary Table 3). The PCR product for $m s r(\mathrm{~A}) / m s r(\mathrm{~B})$ genes, encoding for a macrolide efflux protein and conferring resistance to macrolides and streptogramins B, were identified as the $m s r(\mathrm{C})$ gene by sequencing (Supplementary Table 3). No specific primers targeting the $m s r(\mathrm{C})$ gene were found in the available literature, thus we designed a primer set to detect this gene without the need for sequencing of the PCR product. For both strains, L. agilis KKP 1834 and E. faecium TR2, the specific product of 354-bp with newly designed primer set was obtained. In the case of ampicillin resistant strains, a product of $\sim 297 \mathrm{bp}$ obtained with primers specific for the bla gene was found in one strain (L. plantarum 804). However, the presence of this gene is questionable as the chromatograms obtained by sequencing were unreadable despite the repetition.

\section{DISCUSSION}

It is generally accepted that starter cultures or feed additives contain strains isolated from target raw materials, in accordance with their intended use. The source of probiotic strains used in animals are often the gastrointestinal tract or feces of the same or different animal species (37). Natural microbiota isolated from the host usually more easily and quickly adapts and could be more effective as a probiotic compared to strains from other sources. Nevertheless, numerous studies indicate high prevalence of drug resistance in strains isolated from various animals, including pigs, ruminants, companion animals, poultry, or even wild animals (38-41) as well as 
TABLE 3 | Correlation between resistance phenotype and genotype among studied LAB species $(n=40)$.

\begin{tabular}{|c|c|c|}
\hline Strains & $\begin{array}{l}\text { Resistance } \\
\text { phenotype }^{a}\end{array}$ & $\begin{array}{l}\text { Resistance } \\
\text { genotype }\end{array}$ \\
\hline L. fermentum KKP 2020 & TE & n.d. \\
\hline L. fermentum KKP 830 & & n.d. \\
\hline L. brevis Pat1 & & n.d. \\
\hline L. brevis Solaris & & n.d. \\
\hline L. brevis Pap3/4 & & n.d. \\
\hline L. farraginis E/J & & n.d. \\
\hline P. pentosaceus Pom7 & & n.d. \\
\hline L. buchneri KKP 2047p & K & aph(3")-IIla \\
\hline L. fermentum Sieger & & n.d. \\
\hline L. plantarum KKP 815 & & n.d. \\
\hline L. plantarum KKP 835 & & aph(3")-IIla \\
\hline L. plantarum KKP 870 & & aph(3")-IIIa \\
\hline L. plantarum KKP 872 & & n.d. \\
\hline L. plantarum KKP 2021p & & n.d. \\
\hline L. plantarum KKP 1821 & & n.d. \\
\hline L. plantarum KKP 1822 & & $a p h\left(3^{\prime \prime}\right)-I I I a$ \\
\hline L. plantarum ATCC 8287 & & n.d. \\
\hline L. delbrueckii PCM 490 & & n.d. \\
\hline P. pentosaceus MA & $\mathrm{K}-\mathrm{TE}$ & n.d. \\
\hline L. salivarius KKP 1828 & $\mathrm{~K}-\mathrm{S}$ & n.d. \\
\hline L. rhamnosus KKP 849 & $\mathrm{~K}-\mathrm{CH}$ & n.d. \\
\hline L. plantarum KKP 804 & A & n.d. \\
\hline L. rhamnosus B/J & $\mathrm{GM}-\mathrm{K}$ & n.d. \\
\hline L. acidophilus PCM 2499 & $\mathrm{TE}-\mathrm{S}$ & $\operatorname{tet}(\mathrm{K}), \operatorname{str}(\mathrm{A}) / \operatorname{str}(\mathrm{B})$ \\
\hline P. pentosaceus WN1 & & n.d. \\
\hline E. durans KKP 1586 & $E-C L$ & erm(B) \\
\hline E. faecium TR2 & $T E-E$ & $\begin{array}{l}\operatorname{tet}(\mathrm{M}), \operatorname{msr}(\mathrm{C}) \\
\ln (\mathrm{A})\end{array}$ \\
\hline L. diolivorans KKP 2036p & $T E-K-S$ & aph(3")-IIla \\
\hline L. salivarius KKP 1835 & & $\operatorname{tet}(\mathrm{M}), \operatorname{str}(\mathrm{A}) / \mathrm{str}(\mathrm{B})$ \\
\hline P. pentosaceus KapA & & n.d. \\
\hline P. pentosaceus AG & & n.d. \\
\hline P. acidilactici KKP 1839 & & n.d. \\
\hline L. johnsonii KKP 878 & $\mathrm{TE}-\mathrm{CH}-\mathrm{S}$ & n.d. \\
\hline L. agilis KKP 1834 & $G M-K-S-E$ & $a p h\left(3^{\prime \prime}\right)-I I l a, m s r(C)$ \\
\hline $\begin{array}{l}\text { L. fermentum KKP 811, } \\
\text { KKP 830, KKP } 843\end{array}$ & K & aph(3")-IIIa \\
\hline $\begin{array}{l}\text { L. plantarum KKP } 870 \text {, } \\
\text { KKP } 872\end{array}$ & $\mathrm{CL}$ & $\ln u(A)$ \\
\hline L. plantarum KKP 2021p & $C L$ & $\operatorname{erm}(\mathrm{B})$ \\
\hline
\end{tabular}

${ }^{a} G M$, gentamicin; $K$, kanamycin; TE, tetracycline; $\mathrm{CH}$, chloramphenicol; $\mathrm{A}$, ampicillin; E, erythromycin; CL, clindamycin; S, streptomycin; n.d., tested resistance genes not detected. The strains carrying a resistance gene but phenotypically resistant only in line to cut-off values adopted in previous EFSA guideline (2012) are in bold.

from food of animal origin $(30,42)$. The intensive and irresponsible (especially non-therapeutic) use of antimicrobial agents in animal husbandry and veterinary practice contributes to developing of resistance of gut microbiota and potentially beneficial LAB to antibiotics, including tetracycline, enrofloxacin, ampicillin and MLS antibiotics (macrolides, lincosamides and streptogramins) $(20,40,41,43,44)$. Such strains considered as a reservoir of AMR genes for other commensal bacteria, as well as pathogenic and opportunistically pathogenic species through horizontal gene transfer $(20,45)$. This poses a threat not only to animals, but resistant strains can also be widely distributed through the food chain. Hence, the use of LAB strains isolated from non-intestinal sources has become increasingly attractive and justified. The alternative sources from which beneficial LAB can be isolated are fruits, vegetables and juices, cereals, silages, sourdough, fermented foods and beverages, as well as raw materials and ingredients used to make non-fermented and fermented foods $(37,46)$. The strains selected from various "unconventional" sources meet the criteria for probiotic strains, such as resistance to low $\mathrm{pH}$ and high bile concentrations, adherence capacity to epithelial intestinal cells, and strong antimicrobial activity against pathogenic microorganisms, including bacteriocin-like activity (37). The strains deposited in different Microbial Culture Collections can also be screened to find beneficial LAB strains, although this does not appear to be a common practice. The advantage of strains from the Collections with the status of International Deposit, however, may be their widespread availability. In the present study we used LAB strains from both sources, isolated from animal origin and strains from alternative sources. Most of the strains are deposited in the Microbial Culture Collections.

Recently, the taxonomy of genus Lactobacillus changed significantly. The genus Lactobacillus was one of the most taxonomically complex and extremely heterogeneous and composed 261 genera (as of March 2020) (47). In 2020, based on polyphasic approach (phylogenomic analysis), Zheng et al. (47) reclassified the genus Lactobacillus into 25 genera, including 23 new one. The emended genus of Lactobacillus currently consists of 38 species well adapted to vertebrates' or invertebrates' hosts. The general term lactobacilli are further used to designate bacteria classified to the family Lactobacillaceae until 2020. In our work, we use the names of the former Lactobacillus classification to avoid any confusion and for maintenance of compliment with the nomenclature used in EFSA guidance for microbiological cut-off values. It should be highlighted that the complexity of this phylogenetic group of microorganisms make it difficult to generalize about this genus and contributes to many difficulties in antimicrobial susceptibility testing of these bacteria, regarding the appropriate medium or establish the cut-off values.

LAB species differ significantly in their growth requirements. The M45 (3rd ed.) CLSI (Clinical Laboratory Standards Institute) procedure proposes the use of cation-adjusted Mueller-Hinton broth (CAMHB) supplemented with 2.5 or $5 \%$ lysed horse blood (LHB) as a conventional susceptibility test medium, however, some lactobacilli exhibited weak growth in this medium $(24,48)$. In this study, we used the LSM broth proposed by Klare et al. (24) and in line with ISO/IDF standard procedure, which is more accurate and reproducible for lactobacilli and pediococci $(24,48)$. To distinguish strains with phenotypic resistance from susceptible one, the MIC-off value proposed by the EFSA FEEDAP were used (21). The standard procedures of the European Committee on Antimicrobial Susceptibility Testing (EUCAST) and CLSI provide the same breakpoints for all 
lactobacilli species, while the EFSA's guidelines refer to different groups within LABs, which is relevant considering the great differences in AMR among lactobacilli species. Some species of Lactobacillus are intrinsically resistant to certain antibiotics (e.g., L. plantarum/L. pentosus to streptomycin), while other lactobacilli have variable activity against these antimicrobials (49). Moreover, the breakpoint values are best established for clinically important microorganisms. In the case of lactobacilli, which are infrequently associated with a clinical infection, the collected data are limited, and the guidelines of CLSI and EUCAST provide breakpoints for only four of antibiotics testing (ampicillin, clindamycin, chloramphenicol, and erythromycin).

Antimicrobial susceptibility is a key criterion that must be met when microorganisms are intentionally introduced into the food chain. Numerous data indicate that LAB exhibit highly variable sensitivity to antimicrobial agents. In our study, a total of 65 strains intended for use as a feed or silage additives were tested for their susceptibility to eight selected antimicrobials. Thirty-four tested strains were resistant to at least one antimicrobial agent according to a current EFSA guidance (21).

The high susceptibility of LAB strains to ampicillin (98.5\%) was observed in our study, which is in line with a number of previous data $(29,50,51)$. However, it should be noted that higher resistance for this antibiotic was also noted in lactobacilli, mainly in isolates from poultry and fermented dairy products $(40,41,52)$. The resistance to $\beta$-lactam antibiotics is related to the presence of the bla gene whilst we not confirmed by sequencing the presence of this gene in ampicillin-resistant $L$. plantarum strain. The absence of genes associated with $\beta$-lactam resistance among strains with relatively high MIC values was observed by others $(40,41)$.

High susceptibility among tested LAB strains has been also noted in case of chloramphenicol (96.9\%). This is consistent with many published data $(40,50,51,53)$, although resistance to chloramphenicol in lactobacilli strains isolated from various fermented products has also been reported $(52,54)$. The genotypic resistance to this antibiotic class is usually associated with the presence of cat gene (55) and the occurrence of this gene was noted among some of $\mathrm{LAB}$ strains, including $L$. salivarius, L. johnsonii, L. crispatus, L. reuteri, L. plantarum, L. ingluviei, and $P$. acidilactici $(40,41,54)$. Interestingly, the cat gene was not detected in chloramphenicol-resistant L. rhamnosus and L. johnsonii strains in this study (MIC $=8 \mathrm{mg} / \mathrm{L}$ while the cut-off values is $4 \mathrm{mg} / \mathrm{L}$ ). According to the literature data, the resistance to chloramphenicol may not be related only to the presence of specific genes encoding antibiotic-modifying enzymes, but may also result from diminished expression of many genes, including efflux pumps and oxidative stress-related genes as well as genes encoding outer membrane proteins (56). This phenomenon may be a cause of phenotype and genotype inconsistency observed also in the tested strains.

The occurrence of tetracycline resistance was found in $26.2 \%$ of LAB strains in this study. In other studies conducted in Poland, the percentage of tetracycline-resistant lactobacilli was significantly higher $(40,41,53)$, however, it is not surprising considering that these strains were isolated from poultry. The tet genes are often found in isolates of animal origin $(38,39)$, while in lactobacilli strains isolated from fermented food the resistance to tetracyclines is less frequent, like our findings (29, 52). The prevalence of the tet genes which confers resistance to teracyclines was not significant among tested LAB strains. The tet $(\mathrm{M})$ gene encoded the ribosomal protection protein was found in L. salivarius and E. faecium strains whilst tet $(\mathrm{K})$ encoded the energy-dependent efflux protein was presented in L. acidophilus. Similarly, the tet $(\mathrm{M})$ gene was noted in E. faecium and $L$. salivarius isolates from fermented food in India (57). Nawaz et al. (29) detected this gene in L. plantarum, L. salivarius, $L$. animalis, and $L$. brevis strains isolated from fermented food. This gene was also widespread in L. salivarius, L. agilis, and L. crispatus strains isolated from chickens, turkeys, and pigeons in Poland $(40,41,53)$. Generally, the tet $(\mathrm{M})$ gene is one of the most widespread tetracycline resistance determinants in lactobacilli (55). The tet $(\mathrm{K})$ gene has so far been detected in strains of L. fermentum, L. buchneri, and P. pentosaceus from fermented food $(51,57)$ or L. plantarum, L. salivarius, and L. reuteri isolates from meat pork and poultry in Italy (42). Interestingly, to the best of our knowledge, it seems that tet $(\mathrm{K})$ has not been previously described in L. acidophilus. Among the LAB strains tested, we observed the highest prevalence of phenotypic tetracycline resistance in obligate heterofermentative lactobacilli (64\% strains) and pediococci (100\% strains) (MIC $=16 \mathrm{mg} / \mathrm{L}$ ), but tet resistance genes were not detected in any of the strains. Similar results were reported by other authors $(40,41,58)$. This contradiction between the phenotypic resistance and the absence of the tet genes indicates that tetracycline resistance in these bacteria is likely to be intrinsic and the current microbiological cut-off values for tetracycline should be reevaluated. We propose the MIC $=16 \mathrm{mg} / \mathrm{L}$ as cut-off value for categorization of susceptible and resistant strains within obligate heterofermentative Lactobacillus spp. and Pediococcus spp. The pediococci resistance to tetracyclines was considered as intrinsic also by other authors, who failed to detect the tet genes in strains with MIC values $\geq 16 \mathrm{mg} / \mathrm{L}(32,58-60)$. The high resistance to tetracycline that may be naturally conditioned was also discussed in lactobacilli species $(50,61)$. The intrinsic resistance to tetracyclines is related to the complex regulatory network that modulate the uptake, as well as intracellular accumulation of these antibiotics. The mutations affect to expression and function of activator or repressor of pumps and porins (62). The regulation of intrinsic tetracycline resistance is better characterized in Gram-negative bacteria. The available data about this resistance in Gram-positive species are still poorly understood.

The low rates of resistance to erythromycin (4.6\%) and clindamycin (1.5\%) were observed in tested LAB strains, although other reports showed the high prevalence of resistance to these antimicrobials among lactobacilli strains (40, 41, $43,44,52)$. The $\operatorname{erm}(\mathrm{B})$ gene encoding the ribosomal RNA methylase was detected in L. plantarum and E. durans. The presence of the erm genes is related to exhibit of MLS resistance phenotype (macrolides-lincosamides-streptogramins B), however, only E. durans 1586 was resistant to erythromycin and clindamycin, whereby L. plantarum 2021p was susceptible to both antimicrobials. It is also worth highlighted that the recommendation for clindamycin has been revised and the 
current cut-off value for all lactobacilli is MIC $=4 \mathrm{mg} / \mathrm{L}(21)$. According to the previous guidance (25), this strain would be considered phenotypically resistant to clindamycin, however still susceptible to erythromycin. The presence of the erm genes in strains with phenotypic susceptibility to MLS or only erythromycin was previously reported by others $(40,43,44)$ and may be related to defective expression of this gene $(43,44)$. The relatively high occurrence of $\operatorname{erm}(\mathrm{B})$ was noted for different Lactobacillus and Enterococcus strains isolated from fermented food $(29,57)$. The $\operatorname{erm}(\mathrm{B})$ gene was detected in different lactobacilli (L. plantarum, L. jonsonii, L. salivarius, L. reuteri, L. crispatus, L. amylovorus, L. gallinarum) isolated from broilers $(43,44)$, from swine and poultry meat products $(42)$ or from wine (59). Moreover, in our study two erythromycin-resistant strains, L. agilis 1834 and E. faecium TR2, carried the $m s r(\mathrm{C})$ gene. To the best of our knowledge, this is the first study which reports the presence of this gene in L. agilis. The $m s r(C)$ gene was initially considered as characteristic for E. faecium (63), then it was found in other Enterococcus species, including E. durans, E. lactis, and Enterococcus casseliflavus, and also $P$. pentosaceus and L. fermentum strains (57). The ever frequently occurrence of $m s r(\mathrm{C})$ in different LAB species may be associated with increasingly widespread transfer of this gene between these bacteria. Moreover, two L. plantarum $(870,872)$ and one E. faecium TR2 strains, phenotypically susceptible to clindamycin with $\mathrm{MIC}=4 \mathrm{mg} / \mathrm{L}$, carried the $\ln u(\mathrm{~A})$ gene which encoding lincosamide $O$-nucleotidyltransferase. This gene was found in L. salivarius, L. johnsonii, L. crispatus, L. reuteri, L. agilis, and L. ingluviei $(40,53)$. Similarly, to our results, also Dec et al. (53) noted the $\ln u(A)$ gene in lactobacilli strains susceptible to clindamycin. However, the reason of this relationship remains unknown. In the other hand, the presence of $\ln u(\mathrm{~A})$ gene in strains with the clindamycin MIC of $4 \mathrm{mg} / \mathrm{L}$ may suggest that the previous cut-off values (25) were more suitable to distinguish between a susceptible and a resistant strain. Interestingly, it seems that according to available data $\ln u(\mathrm{~A})$ has not been described so far in L. plantarum and E. faecium species.

In the current study, we observed a high resistance of LAB strains to kanamycin $(32.3 \%)$ and streptomycin (15.4\%), while gentamicin resistance was much less prevalent (3.1\%). Similarly, more frequent occurrence of resistance to streptomycin than to gentamicin was recorded for lactobacilli from chickens and turkeys in Poland $(40,41)$. However, the higher resistance to gentamicin was also reported previously (52). The widespread occurrence of kanamycin-resistant lactobacilli strains of various species has been noted by others $(29,51,53)$. It is generally known that some lactobacilli species display resistance to aminoglycosides. Of the genes that determine resistance to aminoglycosides, the most prevalent was aph $\left(3^{\prime \prime}\right)$-IIIa, encoding the kinase $\operatorname{APH}\left(3^{\prime \prime}\right)$-IIIa, which confer resistance to kanamycin. This gene was found in 6 kanamycin-resistant strains with the MIC value in the range from 128 to $\geq 256 \mathrm{mg} / \mathrm{L}$, including L. plantarum $(835,870,1822)$, L. buchneri 2047p, L. diolivorans 2036p, and L. agilis 1834. The aph $\left(3^{\prime \prime}\right)$-IIIa gene has been previously detected in $L$. delbrueckii subsp. bulgaricus and Streptococcus thermophilus strains from yogurts (64) and $L$. plantarum isolated from wine (59). Surprisingly, the presence of aph( $\left.3^{\prime \prime}\right)$-IIIa was also noted in this study in three L. fermentum strains $(811,830,843)$ with $\mathrm{MIC}=64 \mathrm{mg} / \mathrm{L}$, classified as susceptible to kanamycin. Similarly, to our results, the presence of aminoglycoside resistance genes in phenotypically susceptible lactobacilli have been observed previously (40). Moreover, the $\operatorname{str}(\mathrm{A}) / \operatorname{str}(\mathrm{B})$ genes, encoding the streptomycin kinases $\mathrm{APH}\left(3^{\prime \prime}\right)$ $\mathrm{Ib}$ and $\mathrm{APH}\left(6^{\prime}\right)$-Id, respectively, were noted in L. acidophilus 2499 and L. salivarius 1835. Interestingly, both these strains had MIC values on-fold higher than the cut-off value for streptomycin (32 mg/L for L. acidophilus 2499 and $128 \mathrm{mg} / \mathrm{L}$ for L. salivarius 1835). It should be highlighted, that the $\operatorname{str}(\mathrm{A})$ and $\operatorname{str}(\mathrm{B})$ genes are most frequently linked (65). In this study, we used the primer set which can detect both these genes, whereby a primer forward is complementary to the final part of the $\operatorname{str}(\mathrm{A})$ gene. Therefore, the partial sequence of $\operatorname{str}(\mathrm{B})$ is the main PCR product. The possible occurrence of $\operatorname{str}(\mathrm{A})$ should be confirmed by additional sequencing of longer fragments of this gene or using a specific primer set. It should be mentioned that the vast majority of phenotypically aminoglycoside-resistant strains did not contain any of the known genes that determine this resistance. This phenomenon has been described in other reports (53) and it was suggested that resistance to aminoglycosides, such as kanamycin and streptomycin, is innate in pediococci and some lactobacilli species, including L. fermentum $(32,50)$. The intrinsic aminoglycoside resistance may be associated with the low level of transmembrane potential or its absence that leads to the impaired uptake of these antibiotics. Moreover, the chromosomal mutations which impact to transmembrane electrical potential, were described in Gram-positive bacteria, while in Gram-negative bacteria the variable efflux systems were identified $(32,66)$. Furthermore, a high spontaneous mutation rate to resistance to kanamycin and streptomycin in lactobacilli has been reported (67).

In our study, the phenotypic and genotypic resistance do not correspond in many cases since the strains had the MIC values higher that the microbiological cut-off values but did not have the corresponding resistance genes. These findings are consistent with the results reported in other studies regarding AMR of LAB $(31,40-42,60)$. The simple explanation could be a mutation and mismatches at the primer annealing site that prevents detection of the target resistance gene (68). The phenotype-genotype discrepancies observed in our study could be also explained by the fact that other resistance genes may exist that were not investigated by us; however the number of the known resistance genes continues to increase. The presence of novel, unknown or unusual resistance determinants should also be considered. Moreover, the resistance might be also acquired through some mutations, for example a high spontaneous mutation rate to resistance to aminoglycosides in lactobacilli has been reported (67). Finally, some LAB species could be intrinsically resistant to certain antimicrobials due to inherent structural and functional features which aid their survival in an environment, but are independent of antibiotic selective pressure and are not spread through horizontal gene transfer. Generally, the regulation of intrinsic resistance is better characterized in Gram-negative 
bacteria. The available data about AMR in LAB species, are still poorly understood and the further studies should certainly be carried out to clarify this phenomenon (60).

The recent studies have shown the potential of whole genome sequencing (WGS) for define the accurate genotype and link it to the observed phenotypes (55). WGS analysis for AMR allows detection of a much higher number of resistance markers, including the complete set of resistance genes present in isolates as well as the mutations and mobile genetic elements associated with resistance (69). Nevertheless, WGS analysis is still quite expensive as a technique and creates vast amounts of data and requires specialized bioinformatics expertise. Most authors still rely on phenotypic characterization of isolates and PCR-based detection of AMR genes.

The transfer of AMR genes between different LAB species and other bacteria has been well-documented and demonstrated by in vitro studies with a filter mating technique, as well as by in vivo models of animal rumen and alfalfa plant $(29,70)$. Moreover, it was shown that AMR genes may be transfer from lactobacilli to $E$. faecalis, which is an inhabitant of the animal and human gut, but also a potential pathogen $(70,71)$. Although the transferability of the detected resistance markers was not analyzed in our study and specific mobile genetic elements in tested LAB strains were not identified, the nucleotide sequences of the identified AMR genes showed high similarity or even identity to the AMR genes associated with mobile genetic elements, such as transposons and plasmids, described in LAB and other bacteria, even distantly related, and in some cases pathogenic (Supplementary Table 3). This suggests possible acquisition of detected AMR genes from other bacteria. Furthermore, it can be predicted that detected genes are located on mobile genetic elements. Thus, it is important to consider the possibility of further transfer of the detected AMR genes to other bacteria in the gut via horizontal transfer, which poses a serious health risk to animals and humans.

Despite the improved awareness and understanding of AMR of LAB, and the possibility of its spread through the food chain, this safety criterion is not always taking into consideration by researchers (72-74). The results of the current study highlight that the AMR assessment of LAB strains should be the first and key step in considering their applicability and should precede other studies regarding the beneficial effects of the strains, their usefulness or adaptation criteria.

\section{REFERENCES}

1. Zielińska K, Fabiszewska A, Stefańska I. Different aspects of Lactobacillus inoculants on the improvement of quality and safety of alfalfa silage. Chilean J Agric Res. (2015) 75:298-306. doi: 10.4067/S0718-58392015000400005

2. Markowiak P, Slizewska K. The role of probiotics, prebiotics and synbiotics in animal nutrition. Gut Pathog. (2018) 10:21. doi: 10.1186/s13099-018-0250-0

3. Dincer E, Kivanc M. Characterization of Lactobacillus plantarum strains isolated from Turkish pastirma and possibility to use of food industry. Food Sci Technol. (2019) 40:498-507. doi: 10.1590/fst.05819

\section{CONCLUSION}

Concluding, the presence of acquired AMR genes in the tested LAB strains, including genes that were not previously described in this bacterial group, like those found in pathogenic bacteria, confirms that $\mathrm{LAB}$ are capable of acquiring resistance determinants via horizontal gene transfer. Importantly, many studies show that such genes can be transferred in both directions. While conjugation is the most common way of dissemination of AMR genes, transformation and transduction may also play an important role in this process, even greater than previously thought (45). Therefore, all strains in this study carrying the acquired AMR genes cannot be considered as safe and should not be used as feed or silage additives. On the other hand, the susceptibility of most of the tested strains to the antibiotics recommended by EFSA make them safe for direct use in agriculture and animal husbandry and thus, worth further exploration.

\section{DATA AVAILABILITY STATEMENT}

The original contributions presented in the study are included in the article/Supplementary Material, further inquiries can be directed to the corresponding author.

\section{AUTHOR CONTRIBUTIONS}

IS contributed to conception and design of the study. IS, KJ-P, and MG contributed with resources to the study and performed the collection of isolates. IS, EK, and KJ-P conducted the experiments. IS, EK, and MR analyzed the data. IS and EK wrote the draft of the manuscript. $\mathrm{MB}$ and $\mathrm{MR}$ critically reviewed sections of the manuscript. All authors contributed to manuscript revision, read, and approved the submitted version.

\section{ACKNOWLEDGMENTS}

The authors thank Barbara Chojnacka, Alicja Grzechnik, and Małgorzata Murawska for excellent technical assistance.

\section{SUPPLEMENTARY MATERIAL}

The Supplementary Material for this article can be found online at: https://www.frontiersin.org/articles/10.3389/fvets. 2021.687071/full\#supplementary-material

4. European Union (EU). Register of Feed Additives pursuant to Regulation (EC) No 1831/2003, Edition 10/2020 (288).

5. Jiang S, Cai L, Lv L, Li L. Pediococcus pentosaceus, a future additive or probiotic candidate. Microb Cell Fact. (2021) 20:45. doi: 10.1186/s12934-02101537-y

6. Ben Braïek O, Smaoui S. Enterococci: between emerging pathogens and potential probiotics. Biomed Res Int. (2019) 23:5938210. doi: $10.1155 / 2019 / 5938210$

7. EFSA. Panel on Biological Hazards (BIOHAZ). Update of the list of QPSrecommended biological agents intentionally added to food or feed as notified 
to EFSA 12:suitability of taxonomic units notified to EFSA until March 2020. EFSA J. (2020) 18:6174. doi: 10.2903/j.efsa.2020.6174

8. Sarma PS, Mohanty S. Pediococcus acidilactici pneumonitis and bacteremia in a pregnant woman. J Clin Microbial. (1998) 36:2392-3. doi: 10.1128/JCM.36.8.2392-2393.1998

9. Barton LL, Rider ED, Coen RW. Bacteremic infection with Pediococcus: vancomycin-resistant opportunist. Pediatrics. (2001) 107:775-6. doi: 10.1542/peds.107.4.775

10. Florescu D, Hill L, Sudan D, Iwen PC. Leuconostoc bacteremia in pediatric patients with short bowel syndrome: case series and review. Pediatr Infect Dis J. (2008) 27:1013-9. doi: 10.1097/INF.0b013e3181792621

11. Holmberg P, Hellmich T, Homme J. Pediatric sepsis secondary to an occult dental abscess: a case report. J Emerg Med. (2017) 52:744-8. doi: 10.1016/j.jemermed.2016.12.034

12. Chen F, Zhang Z, Chen J. Infective endocarditis caused by Lactococcus lactis subsp. lactis and Pediococcus pentosaceus: a case report and literature review. Medicine (Baltimore). (2018) 97:e13658. doi: 10.1097/MD.0000000000 013658

13. Groga-Bada P, Mueller I, Foschi F, Gawaz M, Eick Ch. Mitral valve endocarditis due to Lactobacillus. Case Rep Med. (2018) 2018:8613948. doi: $10.1155 / 2018 / 8613948$

14. Datta P, Gupta V, Mohi GK, Chander J, Janmeja AK. Lactobacillus coryniformis causing pulmonary infection in a patient with metastatic small cell carcinoma: case report and review of literature on Lactobacillus pleuro-pulmonary infections. J Clin Diagn Res. (2017) 11:DE01-5. doi: $10.7860 / J C D R / 2017 / 22837.9391$

15. Biesiada G, Krycińska R, Czepiel J, Stazyk K, Kedzierska J, Garlicki A. Meningoencephalitis caused by Lactobacillus plantarum - case report. Int $J$ Neurosci. (2019) 129:715-8. doi: 10.1080/00207454.2018.1482293

16. Citla SD, Gourishankar A. Lactobacillus causing urinary tract infection in a neonate. J Med Cases. (2013) 4:682-5. doi: 10.4021/jmc1454w

17. Cannon JP, Lee TA, Bolanos JT, Danziger LH. Pathogenic relevance of Lactobacillus: a retrospective review of over 200 cases. Eur J Clin Microbiol Infect Dis. (2005) 24:31-40. doi: 10.1007/s10096-004-1253-y

18. Rossi F, Amadoro C, Colavita G. Members of the Lactobacillus Genus Complex (LGC) as opportunistic pathogens: a review. Microoganisms. (2019) 7:126. doi: 10.3390/microorganisms7050126

19. Plumed-Ferrer C, Barberio A, Franklin-Guild R, Werner B, McDonough $\mathrm{P}$, Bennett J, et al. Antimicrobial susceptibilities and random amplified polymorphic DNA-PCR fingerprint characterization of Lactococcus lactis ssp. lactis and Lactococcus garvieae isolated from bovine intramammary infections. J Dairy Sci. (2015) 98:6216-25. doi: 10.3168/jds.2015-9579

20. Devirgiliis C, Barile S, Perozzi G, Antibiotic resistance determinants in the interplay between food and gut microbiota. Genes Nutr. (2011) 6:275-84. doi: 10.1007/s12263-011-0226-x

21. EFSA. Panel on Additives and Products or Substances used in Animal Feed (FEEDAP). Guidance on the characterization of microorganisms used as feed additives or s production organisms. EFSA J. (2018) 6:5206. doi: 10.2903/j.efsa.2018.5206

22. Torriani S, Felis GE, Dellaglio F. Differentiation of Lactobacillus plantarum, L. pentosus, and L.paraplantarum by recA gene sequence analysis and multiplex PCR assay with recA gene-derived primers. Appl Environ Microbiol. (2001) 67:3450-4. doi: 10.1128/AEM.67.8.34503454.2001

23. Ward LJ, Timminis MJ. Differentiation of Lactobacillus casei, Lactobacillus paracasei and Lactobacillus rhamnosus by polymerase chain reaction. Lett Appl Microbiol. (1999) 29:90-2. doi: 10.1046/j.1365-2672.1999. 00586.x

24. Klare I, Konstabel C, Muller-Bertlig S, Reissbrodt R, Huys G, Vancanneyt M, et al. Evaluation of new broth media for microdilution antibiotic susceptibility testing of Lactobacilli, Pediococci, Lactococci, and Bifidobacteria. Appl Environ Microbiol. (2005) 71:8982-6. doi: 10.1128/AEM.71.12.8982-8986.2005

25. EFSA. Panel on Additives and Products or Substances used in Animal Feed (FEEDAP). Guidance on the assessment of bacterial susceptibility to antimicrobials of human and veterinary importance. EFSA J. (2012) 10:2740. doi: 10.2903/j.efsa.2012.2740
26. Clermont D, Chesneau O, De Cespedes G, Horaud T. New tetracycline resistance determinants coding for ribosomal protection in streptococci and nucleotide sequence of tet(T) isolated from Streptococcus pyogenes A498. Antimicrob Agents Chemother. (1997) 41:112-6. doi: 10.1128/AAC.41.1.112

27. Pang Y, Bosch T, Roberts MC. Single polymerase chain reaction for the detection of tetracycline-resistant determinants Tet K and Tet L. Mol Cell Probes. (1994) 8:417-22. doi: 10.1006/mcpr.1994.1059

28. Aminov RI, Garrigues-Jeanjean N, Mackie RI. Molecular ecology of tetracycline resistance: development and validation of primers for detection of tetracycline resistance genes encoding ribosomal protection proteins. Appl Environ Microbiol. (2001) 67:22-32. doi: 10.1128/AEM.67.1.2232.2001

29. Nawaz M, Wang J, Zhou A, Ma C, Wu X, Moore JE, et al. Characterization and transfer of antibiotic resistance in lactic acid bacteria from fermented food products. Curr Microbiol. (2011) 62:1081-9. doi: 10.1007/s00284-010-9856-2

30. Toomey N, Bolton D, Fanning S. Characterization and transferability of antibiotic resistance genes from lactic acid bacteria isolated from Irish pork and beef abattoirs. Res Microbiol. (2010) 161:127-35. doi: 10.1016/j.resmic.2009.12.010

31. Kastner S, Perreten V, Bleuler H, Hugenschimdt G, Lacroix C, Meile L. Antibiotic susceptibility patterns and resistance genes of starter cultures and probiotic bacteria used in food. Syst Appl Microbiol. (2006) 29:145-55. doi: 10.1016/j.syapm.2005.07.009

32. Hummel A, Holzapfel WH, Franz CMAP. Characterisation and transfer of antibiotic resistance genes from enterococci isolated from food. Syst Appl Microbiol. (2007) 30:1-7. doi: 10.1016/j.syapm.2006.02.004

33. Vakulenko SB, Donabedian SM, Voskresenskiy AM, Zervos MJ, Lerner SA, Chow JW. Multiplex PCR for detection of aminoglycoside resistance genes in enterococci. Antimicrob Agents Chemother. (2003) 47:1423-6. doi: 10.1128/AAC.47.4.1423-1426.2003

34. Ouoba LII, Lei V, Jensen, LB. Resistance of potential probiotic lactic acid bacteria and bifidobacteria of African and European origin to antimicrobials: determination and transferability of the resistance genes to other bacteria. Int J Food Microbiol. (2008) 121:217-24. doi: 10.1016/j.ijfoodmicro.2007.11.018

35. Clark NC, Olsvik O, Swenson JM, Spiegel CA, Tenover FC. Detection of a streptomycin/spectinomycin adenylyltransferase gene (aadA) in Enterococcus faecalis. Antimicrob Agents Chemother. (1999) 43:157-60. doi: 10.1128/AAC.43.1.157

36. Sunde $M$, Norström $M$. The genetic background for streptomycin resistance in Escherichia coli influences the distribution of MICs. J Antimicrob Chemother. (2005) 56:87-90. doi: 10.1093/jac/dki150

37. Sornplang P, Piyadeatsoontorn, S. Probiotic isolates from unconventional sources: a review. J Anim Sci Technol. (2016) 58:26. doi: 10.1186/s40781-016-0108-2

38. Chang YC, Tsai CY, Lin CF, Wang YC, Wang IK, Chung TC. Characterization of tetracycline resistance lactobacilli isolated from swine intestines at western area of Taiwan. Anaerobe. (2011) 17:239-45. doi: 10.1016/j.anaerobe.2011.08.001

39. Klose V, Bayer K, Kern C, Goelß F, Fibi S, Wegl G. Antibiotic resistances of intestinal lactobacilli isolated from wild boars. Vet Microbiol. (2014) 168:240-4. doi: 10.1016/j.vetmic.2013.11.014

40. Dec M, Urban-Chmiel R, Stepień-Pyśniak D, Wernicki A. Assessment of antibiotic susceptibility in Lactobacillus isolates from chickens. Gut Pathog. (2017) 9:54. doi: 10.1186/s13099-017-0203-Z

41. Dec M, Nowaczek A, Stepień-Pyśniak D, Wawrzykowski J, Urban-Chmiel R. Identification and antibiotic susceptibility of lactobacilli isolated from turkeys. BMC Microbiol. (2018) 18:168. doi: 10.1186/s12866-018-1269-6

42. Aquilanti L, Garofalo C, Osimani A, Silvestri G, Vignaroli C, Clementi F. Isolation and molecular characterization of antibiotic-resistant lactic acid bacteria from poultry and swine meat products. J Food Prot. (2007) 70:557-65. doi: 10.4315/0362-028X-70.3.557

43. Cauwerts K, Pasmans F, Devriese LA, Haesebrouck F, Decostere A. Cloacal Lactobacillus isolates from broilers often display resistance toward tetracycline antibiotics. Microb Drug Resist. (2006) 12:284-8. doi: $10.1089 / \mathrm{mdr} .2006 .12 .284$

44. Cauwerts K, Pasmans F, Devriese LA, Martel A, Haesebrouck F, Decostere A. Cloacal Lactobacillus isolates from broilers show high prevalence of 
resistance towards macrolide and lincosamide antibiotics. Avian Pathol. (2006) 35:160-4. doi: 10.1080/03079450600598137

45. von Wintersdorff CJ, Penders J, van Niekerk JM, Mills ND, Majumder S, van Alphen LB, et al. Dissemination of antimicrobial resistance in microbial ecosystems through horizontal gene tansfer. Front Microbiol. (2016) 7:173. doi: 10.3389/fmicb.2016.00173

46. Bansal S, Mangal M, Sharma SK, Gupta RK. Non-dairy based probiotics: healthy treat for intestine. Crit Rev Food Sci Nutr. (2016) 56:1856-67. doi: 10.1080/10408398.2013.790780

47. Zheng J, Wittouck S, Salvetti E, Franz CM, Harris HM, Mattarelli P, et al. A taxonomic note on the genus Lactobacillus: description of 23 novel genera, emended description of the genus Lactobacillus Beijerinck 1901, and union of Lactobacillaceae and Leuconostocaceae. Int J Syst Evol Microbiol. (2020) 70:2782-858. doi: 10.1099/ijsem.0.004107

48. Mayrhofer S, Zitz U, Birru FH, Gollan D, Gołoś AK, Kneifel W, et al. Comparison of the CLSI guideline and ISO/IDF standard for antimicrobial susceptibility testing of lactobacilli. Microb Drug Resist. (2014) 20:591-603. doi: 10.1089/mdr.2013.0189

49. Flórez AB, Ergevarn M, Danielsen M, Tosi L, Morelli L, Lingren S, et al. Susceptibility of Lactobacillus plantarum strain to six antibiotics and definition of new susceptibility-resistance cutoff values. Microbial Drug Resist. (2006) 12:252-6. doi: 10.1089/mdr.2006.12.252

50. Danielsen M, Wind A. Susceptibility of Lactobacillus ssp. to antimicrobial agents. Int $J$ Food Microbiol. (2003) 83:1-11. doi: 10.1016/S0168-1605(02)00254-4

51. Anisimova EA, Yarullina DR. Antibiotic resistance of Lactobacillus strains. Curr Microbiol. (2019) 76:1407-16. doi: 10.1007/s00284-019-01769-7

52. Erginkaya Z, Turhan EU, Tatli D. Determination of antibiotic resistance of lactic acid bacteria isolated from traditional Turkish fermented dairy products. Iran J Vet Res. (2018) 19:53-6.

53. Dec M, Stepień-Pyśniak D, Nowaczek A, Puchalski A, Urban-Chmiel R. Phenotypic and genotypic antimicrobial resistance profiles of fecal lactobacilli from domesticated pigeons in Poland. Anaerobe. (2020) 65:102251. doi: 10.1016/j.anaerobe.2020.102251

54. Sukmarini L, Mustopa AZ, Normawati M, Muzdalifah I. Identification of antibiotic-resistance genes from lactic acid bacteria in indonesian fermented foods. HAYATI J Biosci. (2014) 21:144-50. doi: 10.4308/hjb.21.3.144

55. Campedelli I, Mathur H, Salvetti E, Clarke S, Rea MC, Torriani S, et al. Genuswide assessment of antibiotic resistance in Lactobacillus spp. Appl Environ Microbiol. (2018) 85:e01738-18. doi: 10.1128/AEM.01738-18

56. Fernández M, Conde S, de la Torre J, Molina-Santiago C, Ramos JL, Duque E. Mechanisms of resistance to chloramphenicol in Pseudomonas putida KT2440. Antimicrob Agents Chemother. (2012) 56:1001-9. doi: 10.1128/AAC.05398-11

57. Thumu SC, Halami PM. Presence of erythromycin and tetracycline resistance genes in lactic acid bacteria from fermented foods of Indian origin. Antonie Van Leeuwenhoek. (2012) 102:541-51. doi: 10.1007/s10482-012-9749-4

58. Danielsen M, Simpson PJ, O’Connor EB, Ross RP, Stanton C. Susceptibility of Pediococcus ssp. to antimicrobial agents. J Appl Microbiol. (2007) 102:384-9. doi: 10.1111/j.1365-2672.2006.03097.x

59. Rojo-Bezares B, Sáenz Y, Poeta P, Zarazaga M, Ruiz-Larrea F, Torres C. Assessment of antibiotic susceptibility within lactic acid bacteria strains isolated from wine. Int J Food Microbiol. (2006) 111:234-40. doi: 10.1016/j.ijfoodmicro.2006.06.007

60. Lüdin P, Roetschi A, Wüthrich D, Bruggmann R, Berthoud H, Shani N. Update on tetracycline susceptibility of Pediococcus acidilactici based on strains isolated from swiss cheese and whey. J Food Prot. (2018) 81:1582-9. doi: 10.4315/0362-028X.JFP-18-160

61. Gevers D, Huys G, Devlieghere F, Uyttendaele M, Debevere J, Swings J. Isolation and identification of tetracycline resistant lactic acid bacteria from pre-packed sliced meat products. Syst Appl Microbiol. (2000) 23:279-84. doi: 10.1016/S0723-2020(00) 80015-6
62. Grossman TH. Tetracycline antibiotics and resistance. Cold Spring Harb Perspect Med. (2016) 6:a025387. doi: 10.1101/cshperspect.a025387

63. Portillo A, Ruiz-Larrea F, Zarazaga M, Alonso A, Martinez JL, Torres C. Macrolide resistance genes in Enterococcus spp. Antimicrob Agents Chemother. (2000) 44:967-71. doi: 10.1128/AAC.44.4.967-971.2000

64. Zhou N, Zhang JX, Fan MT, Wang J, Guo G, Wei XY. Antibiotic resistance of lactic acid bacteria isolated from Chinese yogurts. J Dairy Sci. (2012) 95:4775-83. doi: 10.3168/jds.2011-5271

65. Chiou CS, Jones AL. Expression and identification of the $\operatorname{str} A-\operatorname{str} B$ gene pair from Streptomycin-resistant Erwinia Amylovora. Gene. (1995) 152:47-51. doi: 10.1016/0378-1119(94)00721-4

66. Vakulenko SB, Mobashery S. Versatility of aminoglycosides and prospects for their future. Clin Microbiol Rev. (2003) 16:430-50. doi: 10.1128/CMR.16.3.430-450.2003

67. Curragh HJ, Collins MA. High levels of spontaneous drug resistance in Lactobacillus. J Appl Bacteriol. (1992) 73:31-6. doi: 10.1111/j.1365-2672.1992.tb04965.x

68. Kwiecień E, Stefańska I, Chrobak-Chmiel D, Kizerwetter-Swida M, Moroz A, Olech W, et al. Trueperell pyogenes isolates from livestock and European bison (Bison bonasus) as a reservoir of tetracycline resistance determinants. Antibiotics (Basel). (2021) 10:380. doi: 10.3390/antibiotics10040380

69. Cooper AL, Low AJ, Koziol AG, Thomas MC, Leclair D, Tamber S, et al. Systematic evaluation of whole genome sequence-based predictions of Salmonella serotype and antimicrobial resistance. Front Microbiol. (2020) 11:549. doi: 10.3389/fmicb.2020.00549

70. Toomey N, Monaghan A, Fanning S, Bolton D. Transfer of antibiotic resistance marker genes between lactic acid bacteria in model rumen and plant environments. Appl Environ Microbiol. (2009) 75:3146-52. doi: 10.1128/AEM.02471-08

71. Jacobsen L, Wilcks A, Hammer K, Huys G, Gevers D, Andersen SR. Horizontal transfer of $\operatorname{tet}(M)$ and $\operatorname{erm}(B)$ resistance plasmids from food strains of Lactobacillus plantarum to Enterococcus faecalis $\mathrm{JH} 2-2$ in the gastrointestinal tract of gnotobiotic rats. FEMS Microbiol Ecol. (2007) 59:15866. doi: 10.1111/j.1574-6941.2006.00212.x

72. Sirichokchatchawan W, Pupa P, Praechansri P, Am-In N, Tanasupawat S, Sonthayanon P, et al. Autochthonous lactic acid bacteria isolated from pig faeces in Thailand show probiotic properties and antibacterial activity against enteric pathogenic bacteria. Microb Pathog. (2018) 119:208-15. doi: 10.1016/j.micpath.2018.04.031

73. Mandal A, Mandal RK, Yang Y, Khatri B, Kong BW, Kwon YM. In vitro characterization of chicken gut bacterial isolates for probiotic potentials. Poult Sci. (2021) 100:1083-92. doi: 10.1016/j.psj.2020.11.025

74. Lin CF, Lin MY, Lin CN, Chiou MT, Chen JW, Yang KC, et al. Potential probiotic of Lactobacillus strains isolated from the intestinal tracts of pigs and feces of dogs with antibacterial activity against multidrug-resistant pathogenic bacteria. Arch Microbiol. (2020) 202:1849-60. doi: 10.1007/s00203-020-01908-w

Conflict of Interest: KJ-P is employed by Prof. Waclaw Dabrowski Institute of Agriculture and Food Biotechnology - State Research Institute, which owns the Industrial Microbial Cultures Collection (KKP).

The remaining authors declare that the research was conducted in the absence of any commercial or financial relationships that could be construed as a potential conflict of interest.

Copyright (c) 2021 Stefańska, Kwiecień, Jóźwiak-Piasecka, Garbowska, Binek and Rzewuska. This is an open-access article distributed under the terms of the Creative Commons Attribution License (CC BY). The use, distribution or reproduction in other forums is permitted, provided the original author(s) and the copyright owner(s) are credited and that the original publication in this journal is cited, in accordance with accepted academic practice. No use, distribution or reproduction is permitted which does not comply with these terms. 